\title{
EPIDEMIOLOGY OF HUMAN INFECTION WITH THE NOVEL VIRUS INFLUENZA A (H1H1) IN THE HOSPITAL DAS CLÍNICAS, SÃO PAULO, BRAZIL - JUNE-SEPTEMBER 2009
}

\author{
Denise Schout, 'Ludhmila Abrahao Hajjar, ${ }^{\text {II }}$ Filomena Regina Barbosa Gomes

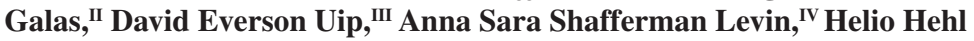 \\ Caiaffa Filho, ${ }^{\mathrm{V}}$ Pedro Takanori Sakane, ${ }^{\mathrm{VI}}$ Carlos Alberto Suslik, ${ }^{\mathrm{VII}}$ Jose Manoel \\ de Camargo Teixeira, ${ }^{\mathrm{VII}}$ Eloisa Bonfa, ${ }^{\mathrm{IX}}$ Antonio Alci Barone, ${ }^{\mathrm{IV}}$ Milton de \\ Arruda Martins, ${ }^{\mathrm{IX}}$ Marcos Boulos, ${ }^{\mathrm{X}}$ and Jose Otavio Costa Auler Jr. ${ }^{\mathrm{XI}}$
}

doi: $10.1590 / \mathrm{S} 1807-59322009001000014$

Schout D, Hajjar LA, Galas FRBG, Uip DE, Levin ASS, Caiaffa-Filho HH et al. Epidemiology of human infection with the novel virus influenza A (H1N1) In the Hospital das Clínicas, São Paulo, Brazil - June-September 2009. Clinics. 2009;64(10):1025-30.

The pandemic novel influenza A (H1N1) infection was considered widespread in Brazil on July 16, 2009. Since then, 46,810 cases of acute respiratory syndrome have been reported in Brazil, most of them concentrated in São Paulo. Through September 16, we have confirmed 9,249 cases of novel influenza A H1N1in Brazil, including 699 deaths. The mortality rate observed in Brazil is $0.47 / 100,000$ inhabitants and varies according to region. In this period, São Paulo registered 3733 cases (40.3\% of the total) of novel influenza A (H1N1) infection and 327 deaths, reflecting a mortality rate of 0.79/100,000 inhabitants.

The Hospital das Clínicas da Faculdade de Medicina da Universidade de São Paulo (HC) is a reference center for H1N1 cases in São Paulo. During the winter of 2009, 472 patients in this hospital were diagnosed with H1N1 infection; of these, 210 were admitted, and 16 died. To control this pandemic and to provide adequate care for these patients, the Hospital das Clínicas implemented "bundles" including prevention strategies, an epidemiologic surveillance service, availability of fast diagnosis, antiviral treatment and training of staff.

The purpose of this manuscript is to describe the epidemiologic features of novel human influenza A (H1N1) infection in the Hospital das Clínicas da Faculdade de Medicina da Universidade de São Paulo during the winter period of the 2009 pandemic.

KEYWORDS: Epidemiology; H1N1 infection; Hospital das Clínicas; Pandemic.

\section{INTRODUCTION}

In April 2009, the first cases of human infection with a

\footnotetext{
${ }^{\text {I }}$ Department of Preventive Medicine, Epidemiology Service - Hospital das Clínicas da Faculdade de Medicina da Universidade de São Paulo - São Paulo/SP, Brazil.

II Department of Anesthesiology, InCor-Heart Institute and Instituto do Câncer do Estado de São Paulo - Hospital das Clínicas da Faculdade de Medicina da Universidade de São Paulo - São Paulo/SP, Brazil.


da Universidade de São Paulo - São Paulo/SP, Brazil.

${ }^{\text {IV }}$ Department of Infectious Diseases - Hospital das Clínicas da Faculdade de Medicina da Universidade de São Paulo - São Paulo/SP, Brazil.

v Department of Pathology - Hospital das Clínicas da Faculdade de Medicina da Universidade de São Paulo - São Paulo/SP, Brazil.

vi Instituto da Criança - Hospital das Clínicas da Faculdade de Medicina da Universidade de São Paulo - São Paulo/SP, Brazil.
}

novel influenza A $(\mathrm{H} 1 \mathrm{~N} 1)$ virus were reported in the United States and Mexico., ${ }^{1,2}$ The novel H1N1 virus possesses distinct molecular properties of human, avian, and swine

\footnotetext{
VII Hospital das Clínicas da Faculdade de Medicina da Universidade de São Paulo - São Paulo/SP, Brazil.

vIII Hospital das Clínicas da Faculdade de Medicina da Universidade de São Paulo - São Paulo/SP, Brazil.

${ }^{\mathrm{Ix}}$ Department of Internal Medicine - Hospital das Clínicas da Faculdade de Medicina da Universidade de São Paulo - São Paulo/SP, Brazil.

${ }^{\mathrm{x}}$ Faculdade de Medicina da Universidade de São Paulo - São Paulo/SP, Brazil.

${ }^{x ı}$ Hospital das Clínicas da Faculdade de Medicina da Universidade de São

Paulo - São Paulo/SP, Brazil.

Email: diretoria.clinica@hcnet.usp.br

Tel.: 55113069.6431

Received for publication on September 24, 2009.

Accepted for publication on October 01, 2009.
} 
influenza and is a highly transmissible and mutable virus known as the swine origin influenza virus (S-OIV). ${ }^{3,4}$

As of September 13, 2009, novel H1N1 has caused 296,471 virologically confirmed human cases, resulting in at least 3,486 deaths in countries worldwide. ${ }^{5}$ Since April of this year, human health agencies worldwide have been attempting to deal with this new pandemic disease, establishing prevention strategies, improving diagnostic methods and adopting therapeutic measures. ${ }^{6,7,8}$

Pandemic novel influenza A (H1N1) infection was considered widespread in Brazil on July 16. ${ }^{9}$ Since the first reported case of H1N1 infection, Brazil's Ministry of Health, as suggested by the World Health Organization, has maintained continuous epidemiologic vigilance of cases of acute respiratory syndrome (ARS). This strategy of vigilance considers any persons with flu syndrome as potential cases of influenza A (H1N1), designating as potential cases all individuals who present with acute respiratory syndrome with cough, dyspnea, and fever. ${ }^{9}$

The Hospital das Clínicas da Faculdade de Medicina da Universidade de São Paulo (HC) is the largest tertiary health care facility in Brazil and is a reference center for H1N1 cases in Sao Paulo. To help control the pandemic, the Hospital das Clínicas Council created the "Cabinet Crisis", a group of healthcare professionals who continuously evaluate "bundles", groups of interventions and advertisements for control of S-OIV infection, to obtain better outcomes in the management of this disease. Two of the main responsibilities of this committee are to provide continuous epidemiologic vigilance and to acquire expertise in performing adequate diagnosis and treatment of patients.

This manuscript describes the epidemiologic features of novel human influenza A (H1N1) infection in the Hospital das Clínicas da Faculdade de Medicina da Universidade de São Paulo during the winter period of the 2009 pandemic.

\section{EPIDEMIOLOGY IN BRAZIL}

Currently, 46,810 cases of acute respiratory syndrome (ARS) have been reported in Brazil. ${ }^{9}$ Of these, 9,249 (20\%) patients presented infection with novel influenza A (H1N1) virus. Seasonal influenza A infection was confirmed in 1,152 $(2.5 \%)$ patients. ${ }^{9}$ All states in Brazil except for Sergipe reported cases. H1N1 occurrence is concentrated in the states of Paraná, Sao Paulo and Rio Grande do Sul. A peak of incidence was observed in August, with a later decrease (Figure 1).

Sao Paulo is the most populated state in Brazil and presents the majority of reported $\mathrm{H} 1 \mathrm{~N} 1$ cases. As of September 12, 2009, 13,069 cases of acute respiratory syndrome, of which 3,733 were due to novel influenza A

\begin{tabular}{|l|l|l|l|l|l|l|}
\hline Week & $\begin{array}{l}31 \\
(8 / 2 \text { to } 8 / 8)\end{array}$ & $\begin{array}{l}32 \\
(8 / 9 \text { to } 8 / 15)\end{array}$ & $\begin{array}{l}33 \\
(8 / 16 \text { to } 8 / 22)\end{array}$ & $\begin{array}{l}34 \\
(8 / 23 \text { to } 8 / 29)\end{array}$ & $\begin{array}{l}35 \\
(8 / 30 \text { to } 9 / 5)\end{array}$ & $\begin{array}{l}36 \\
(9 / 6 \text { to 9/12) }\end{array}$ \\
\hline $\begin{array}{l}\text { Influenza A } \\
(\mathrm{H} 1 \mathrm{~N} 1)\end{array}$ & 2.283 & 1.545 & 1.028 & 837 & 490 & 35 \\
\hline
\end{tabular}

Figure 1 - Distribution of cases of acute respiratory syndrome in Brazil according to epidemiologic week from week 31 to 36, 2009 (data obtained from Ministry of Health of Brazil) ${ }^{9}$

(H1N1) infection, were registered in São Paulo. São Paulo state registered $40.3 \%(3,733$ of 9,249$)$ of the confirmed cases in Brazil, with the majority identified in the city. Compared to Paraná and Rio Grande do Sul, São Paulo presents the lowest mortality rate - $(0.79 / 100,000$ inhabitants versus $1.36 / 100,000$ and 2.08/100,000 inhabitants, respectively). ${ }^{9,10}$

The mortality rate by age and gender for H1N1 cases in Sao Paulo state is shown in Figure 2. Females and individuals 20-39 years of age present the highest risk of mortality. These data are similar to those reported in Brazil and worldwide. In Brazil, the mortality rate is $0.47 / 100,000$ inhabitants and varies according to region. Argentina, Paraguay, Australia and Chile present higher rates of mortality $(1.27,0.81,0.80$ and $0.77 / 100,000$ inhabitants, respectively). ${ }^{9}$

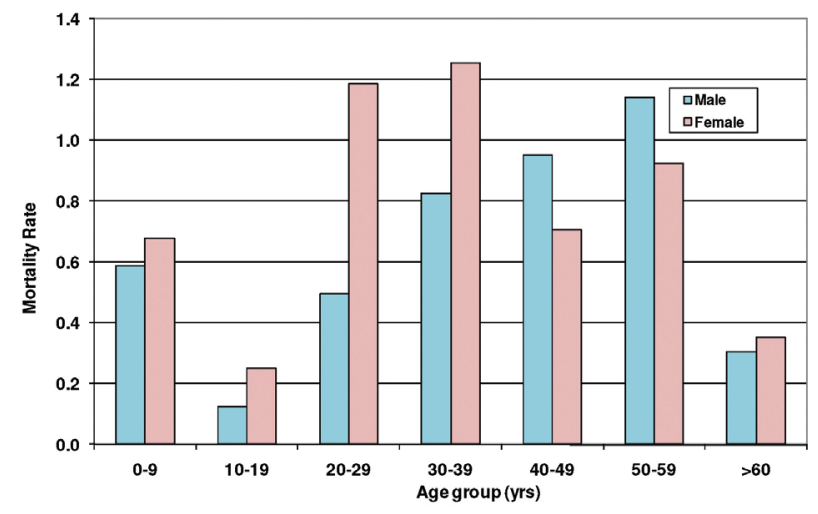

Figure 2 - Mortality rate by sex and age group (per 100,000 inhabitants) São Paulo state - Brazil, as of 5th September

In Brazil, among the reported cases, H1N1-infected individuals tend to be young, with a median age of 26 years. Most patients are 15-49 years of age. The observed age distribution is unusual and differs from that seen with seasonal influenza, being skewed toward younger age groups. With respect to gender distribution, $57.5 \%$ of the confirmed cases of novel virus influenza A (H1N1) occur in women. 9,10 $^{2}$

Following the first reported case on July 16, the Ministry of Health initiated a nationwide global action plan with the goal of offering information on prevention and providing rapid diagnosis and adequate treatment. ${ }^{11}$ 


\section{EPIDEMIOLOGIC FEATURES OF H1N1 CASES SEEN IN THE HOSPITAL DAS CLÍNICAS}

The Hospital das Clínicas da Faculdade de Medicina da Universidade de São Paulo (HC) is the largest tertiary health care hospital in Brazil, with 1953 regular beds, 351 ICU beds, and 63,631 patients admitted per year. The $\mathrm{HC}$ is a complex of 5 medical institutes (Instituto Central, Instituto de Ortopedia, Instituto de Radiologia, Instituto da Criança, Instituto de Psiquiatria) and other associated hospitals (Hospital de Suzano e de Cotoxó) and is a reference center for H1N1 cases in São Paulo. Two other hospitals are linked to the HC: the Hospital do Cancer do Estado de São Paulo and Hospital Emílio Ribas. Both participated in the use of $\mathrm{HC}$ "bundles" aimed at controlling the pandemic. ("Bundles" are groups of interventions and advertisements being used in order to obtain better outcomes in the management of this disease).

From June 2009 through September 2009, the Hospital das Clínicas da Faculdade de Medicina da Universidade de Sao Paulo registered 1500 cases of novel human influenza A (H1N1) infection and confirmed 472 cases (Table 1). Of these patients, $210(46 \%)$ were admitted to regular ward or intensive care units. The remaining patients were diagnosed at the emergency department (216-45\%) or at ambulatory care centers $(46-9 \%)$ and received home treatment after being provided with adequate information (Table 1).

Of 122 confirmed cases of infection with seasonal influenza A, 53 patients (43\%) were hospitalized. During this period, a high incidence of hospital admission due to respiratory symptoms (700 patients) occurred; 210 of the admitted patients were confirmed to have S-OIV infection (Figure 3). Analysis of the distribution of cases by week revealed that a peak of incidence occurred in August and that the number of cases progressively decreased after week 32 (Figure 3).

At the beginning of the pandemic, the cases reported by the Hospital das Clínicas most frequently involved mild forms of the disease; most of the attending was done at the

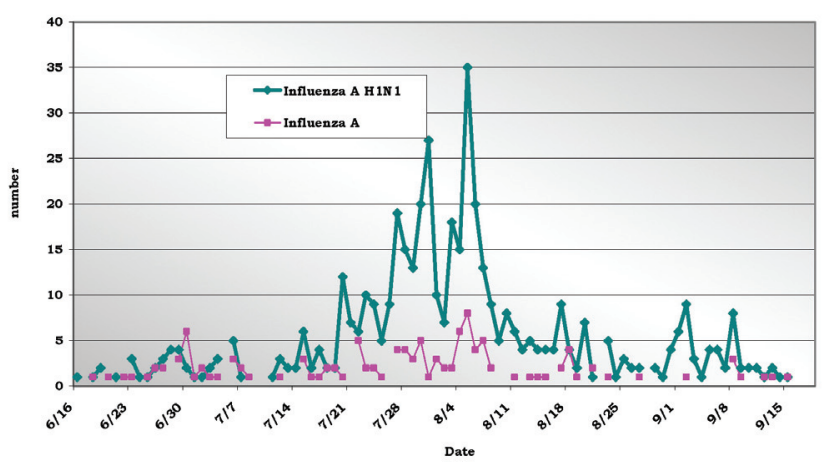

Figure 3 - Distribution of confirmed cases of seasonal Influenza A and Influenza A (H1N1) admitted in the HC-FMUSP - 06/16 to 09/18 - 2009

emergency room, and the patients were discharged. After July, we observed an increase in hospital admissions due to a higher frequency of more severe cases and an increased number occurring in high risk populations (Figure 4).

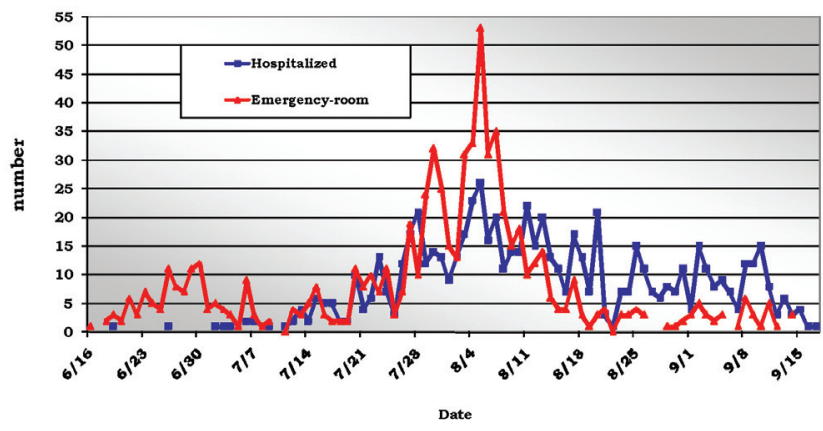

Figure 4 - Distribution of reportable cases in the HC-FMUSP according to the local of attending - June 16 to September 18

More than half of our patients were between 0 and 29 years of age and were female (Table 2); this distribution is similar to the age and gender distribution reported in other series. ${ }^{12}$ Perhaps due to the status of this hospital as a reference center for $\mathrm{H} 1 \mathrm{~N} 1$ treatment, most of the patients attended in the $\mathrm{HC}(85.5 \%)$ presented at least one comorbidity. Immunosuppression, chronic respiratory disease, and cardiovascular disease were the most frequent risk factors present in these patients, occurring in $15.6 \%, 14.3 \%$

Table 1 - Cases reported by final diagnosis and local of attendance - Hospital das Clinicas - FMUSP - June 16 to September 18,2009

\begin{tabular}{lcccccccc}
\hline Diagnosis & \multicolumn{2}{c}{ Emergency room } & \multicolumn{2}{c}{ Hospitaliza-tion } & \multicolumn{2}{c}{ Ambulatory } & \multicolumn{2}{c}{ TOTAL } \\
\cline { 2 - 8 } & $\mathbf{n}^{\mathbf{0}}$ & $\boldsymbol{\%}$ & $\mathbf{n}^{\mathbf{0}}$ & $\boldsymbol{\%}$ & $\mathbf{n}^{\mathbf{0}}$ & $\boldsymbol{\%}$ & $\mathbf{n}^{\mathbf{0}}$ & $\mathbf{\%}$ \\
\hline Novel Influenza A H1N1 & 216 & 46 & 210 & 45 & 46 & 9 & $\mathbf{4 7 2}$ & $\mathbf{3 1 . 5}$ \\
Influenza A & 65 & 53 & 53 & 43 & 4 & 3.2 & $\mathbf{1 2 2}$ & $\mathbf{8 . 1}$ \\
Other diagnoses & 344 & 38 & 433 & 48 & 125 & 14 & $\mathbf{9 0 2}$ & $\mathbf{6 0 . 1}$ \\
Ongoing investigation & 0 & 0 & 4 & 0.6 & 0 & 0 & $\mathbf{4}$ & $\mathbf{0 . 4}$ \\
\hline Total & $\mathbf{6 2 5}$ & $\mathbf{1 0 0}$ & $\mathbf{7 0 0}$ & $\mathbf{1 0 0}$ & $\mathbf{1 7 5}$ & $\mathbf{1 0 0}$ & $\mathbf{1 5 0 0}$ & $\mathbf{1 0 0}$ \\
\hline
\end{tabular}


Table 2 - Clinical and epidemiologic aspects of 472 confirmed cases of novel Influenza A (H1N1) - Hospital das Clinicas FMUSP - June 16 to September 18, 2009

\begin{tabular}{|c|c|c|}
\hline \multirow{2}{*}{ Variable } & \multicolumn{2}{|c|}{ Novel Influenza A H1N1 } \\
\hline & $n^{\circ}$ & $\%$ \\
\hline \multicolumn{3}{|l|}{ Gender } \\
\hline Female & 262 & 55.5 \\
\hline \multicolumn{3}{|l|}{ Age } \\
\hline $0-9$ & 107 & 22.7 \\
\hline $10-19$ & 77 & 16.3 \\
\hline $20-29$ & 98 & 20.8 \\
\hline $30-39$ & 60 & 12.7 \\
\hline $40-49$ & 50 & 10.6 \\
\hline $50-59$ & 50 & 10.6 \\
\hline$>=60$ & 30 & 6.4 \\
\hline Total & 472 & 100.0 \\
\hline Median age & $\begin{array}{c}25 \\
(<1 \text { to } 88 \\
\text { years })\end{array}$ & \\
\hline \multicolumn{3}{|l|}{ Pre-existing conditions } \\
\hline Immunosuppression & 72 & 15.3 \\
\hline Chronic respiratory disease & 69 & 14.6 \\
\hline Chronic cardiovascular disease & 58 & 12.3 \\
\hline Heath care professional & 40 & 8.5 \\
\hline Pregnancy & 35 & 7.4 \\
\hline Chronic metabolic disorder & 22 & 4.7 \\
\hline Cancer & 14 & 3.0 \\
\hline Smoke & 15 & 3.2 \\
\hline Transplants & 10 & 2.1 \\
\hline Without comorbidity & 73 & 15.5 \\
\hline \multicolumn{3}{|l|}{ Presenting manifestations } \\
\hline Cough & 398 & 84.3 \\
\hline Fever & 378 & 80.1 \\
\hline Rhinorrhoea & 229 & 48.5 \\
\hline Dyspnea & 198 & 41.9 \\
\hline Myalgia & 186 & 39.4 \\
\hline Sore throat & 123 & 26.1 \\
\hline Arthralgia & 61 & 12.9 \\
\hline Diarrhea & 37 & 7.8 \\
\hline Conjunctivitis & 34 & 7.2 \\
\hline Headache & 31 & 6.6 \\
\hline
\end{tabular}

and $12.3 \%$ of the patients, respectively (Table 2 ). These groups of risk are similar to related in the literature. ${ }^{13,14,15}$ We reported 35 cases in pregnant women, including 2 deaths. One of the pregnant women who died presented a very severe form of the disease characterized by acute respiratory distress syndrome, renal failure and hepatic insufficiency. The severity of H1N1 infection in pregnancy has been reported by other authors and may be due to the frequent occurrence if some degree of immunosupression in pregnant women. ${ }^{16}$ In Brazil, 856 pregnant women were affected, and 91 died. ${ }^{9}$

Previous data on S-OIV infection in humans have shown that the majority of affected patients are healthy individuals who present an influenza-like illness, with fever, cough and myalgia occurring in nearly $100 \%$ of cases. ${ }^{17}$ Cough, fever, rhinorrhoea, dyspnea and myalgia were the symptoms most frequently encountered in the cases from HC (Table 2).

Of 472 confirmed cases of novel H1N1 infection seen at the Hospital das Clínicas, 210 were admitted due to severity of symptoms or due to the patient's co-morbidities. Of these, 176 cases $(83.8 \%)$ were discharged recovered, 13 are still hospitalized (6.2\%), 5 were transferred to other institutions (2.4\%), and 16 (7.6\%) died (Table 3). All the deaths, with the exception of one, were related to a severe form of lung disease characterized by acute respiratory distress syndrome, refractory hypoxemia, shock and ultimately multiple organ failure.

As previously stated, the Hospital das Clínicas is a complex of institutes and associated hospitals. As a result of a measure adopted by the "Crisis Cabinet" to control the pandemic, the attending and human resources devoted to control and treatment of H1N1 infection, including a specialized structure of intensive care units and regular wards, were concentrated in the Instituto Central. Most of the cases ( 86 patients $-41 \%$ ) were admitted to the Instituto Central and presented a median length of stay of 9.4 days (Table 4). The Instituto da Criança admitted 64 cases (30\%), with 5.7 days median length of stay. The other institutes and hospitals presented lower numbers (Table 4). The deaths were registered in Instituto Central (8), Instituto do Câncer (5) and in the Instituto do Coração (3).

In the last 30 days, the $\mathrm{HC}$ epidemiologic surveillance service describes a significant decrease in the number of cases of novel human H1N1 infection. The Ministry of Health in Brazil registers a similar control of the pandemic, with just a few cases reported since week 35 (30 August to 05 September). In the Hospital das Clínicas, the strategy implemented by the "Crisis Cabinet" included:

1. Periodic meetings among healthcare professionals from all institutions, including directors, professors, epidemiologists, infectologists, and intensive care physicians, to discuss new data and information about the disease.

2. Continuous local epidemiologic surveillance to collect and analyze data for assessment of the impact of the virus and identification of groups at an increased risk of complications. 
Table 3 - Hospitalized cases of acute respiratory syndrome and the clinical endpoint after final diagnostic - Hospital das Clinicas - FMUSP - June, 16 to September, 18 - 2009

\begin{tabular}{lcccccccc}
\hline Type of discharge & \multicolumn{2}{c}{ Novel Influenza A } & \multicolumn{2}{c}{ Influenza A } & \multicolumn{2}{c}{ Others diagnostics } & \multicolumn{2}{c}{ Total** } \\
& $\mathrm{n}^{\text {o }}$ & $\%$ & $\mathrm{n}^{\text {o }}$ & $\%$ & $\mathrm{n}^{\text {o }}$ & $\%$ & $\mathrm{n}^{\text {o }}$ & $\%^{2}$ \\
\hline Discharged & 176 & 83.8 & 44 & 83.0 & 299 & 69.1 & 519 & 74.6 \\
Death* & $\mathbf{1 6}$ & $\mathbf{7 . 6}$ & $\mathbf{2}$ & $\mathbf{3 . 8}$ & $\mathbf{5 9}$ & $\mathbf{1 3 . 6}$ & $\mathbf{7 7}$ & $\mathbf{1 1 . 1}$ \\
Extern transfer & 5 & 2.4 & 6 & 5.7 & 8 & 1.8 & 16 & 2.3 \\
Hospitalized & 13 & 6.2 & 4 & 7.5 & 67 & 15.5 & 84 & 12.1 \\
\hline Total** & 210 & 100.0 & 53 & 100.0 & 433 & 100.0 & 696 & 100.0 \\
\hline
\end{tabular}

$* 1$ death of confirmed case died of cause not related to (H1N1) infection; $* * 4$ cases waiting for final laboratory diagnosis.

Table 4 - Number of hospitalized patients with novel Influenza H1N1 and length of stay according to the Institute or associated Hospital in the HC-FMUSP- June 16, to September, 18 - 2009

\begin{tabular}{|c|c|c|c|c|c|c|c|c|}
\hline \multirow[t]{3}{*}{ Hospital } & \multicolumn{8}{|c|}{ Final Diagnostic } \\
\hline & \multicolumn{2}{|c|}{ Novel Influenza A } & \multicolumn{2}{|c|}{ Influenza A } & \multicolumn{2}{|c|}{ Others diagnostics } & \multicolumn{2}{|c|}{ Total* } \\
\hline & $n^{\circ}$ & LOS & $\mathrm{n}^{\mathrm{o}}$ & LOS & $\mathrm{n}^{\mathrm{o}}$ & LOS & $\mathrm{n}^{\circ}$ & LOS \\
\hline Instituto Central & 86 & 9.4 & 25 & 7.4 & 148 & 7.2 & 259 & 7.9 \\
\hline Instituto da Criança & 64 & 5.7 & 13 & 16.5 & 113 & 6.9 & 190 & 7.1 \\
\hline Instituto do Coração & 31 & 8.7 & 6 & 8.5 & 75 & 8.8 & 112 & 8.7 \\
\hline Instituto do Câncer & 9 & 4.1 & 5 & 3.6 & 51 & 7.3 & 65 & 6.6 \\
\hline Hospital de Cotoxó & 13 & 10.6 & 1 & 0.0 & 28 & 6.3 & 42 & 7.5 \\
\hline Instituto de Ortopedia e Traumatologia & 1 & 0.0 & 0 & - & 2 & 10.5 & 3 & 7.0 \\
\hline Instituto da Criança - ITACI & 5 & 8.6 & 3 & 12.0 & 8 & 6.6 & 16 & 8.3 \\
\hline Instituto de Psiquiatria & 1 & 1.0 & 0 & - & 6 & 9.3 & 7 & 8.1 \\
\hline Hospital de suzano & 0 & - & 0 & - & 2 & 1.0 & 2 & 1.0 \\
\hline Total** & 210 & 7.4 & 53 & 9.5 & 433 & 6.0 & 696 & 7.7 \\
\hline
\end{tabular}

**4 cases waiting for final laboratory diagnosis. LOS = lenght of stay in days

3. Provision of information about novel influenza A infection, symptoms, diagnosis, and prevention to all professionals and patients.

4. Availability of real-time RT-PCR for (H1N1) virus in admitted patients.

5. Reduction in the number of daily visits of families to the hospital.

6. Implementation of hygienic measures including alcoholbased hand cleaner, gloves, and masks.

7. Internet published recommendations on the management of infection (www.hcnet.usp.br)

8. Specific units for the care of patients with suspected or confirmed S-OIV infection including emergency room attending, regular ward and specialized intensive care units.

9. Guidance for staff and coworkers to limit contact with other people when symptoms are present.

10. Risk group-specialized protocols for the treatment of pregnant women, children, immunocompromised patients, and those with chronic diseases.
11. Immediate availability of antiviral therapy.

The diagnostic approach adopted in the HC includes the full-time availability of a real-time transcriptase reverse polymerase chain reaction (RT-PCR) for novel influenza A (H1N1). ${ }^{18,19}$ Samples for laboratory tests are obtained from the deep nasal passages (nasal swab), nasopharynx (nasopharyngeal swab), or bronchial aspirate, if available. As recommended, the test is performed in the following cases: ${ }^{20}$ a) patients who require hospitalization;

b) patients with risk factors for severe forms of disease;

c) patients in an individualized protocol, according to clinical judgment.

In the Hospital das Clínicas, antiviral therapy is directed to specific groups:

1. All hospitalized patients with confirmed, probable, or suspected novel influenza (H1N1).

a. Patients who are at a higher risk for complications:

- Individuals with underlying chronic diseases: asthma, chronic obstructive airway disease, diabe- 
tes, immunocompromise, chronic cardiovascular disease, chronic renal failure, epilepsy, obesity, and cancer.

- Pregnant women.

- Children under two years of age.

- Individuals $>65$ years of age.

We hypothesize that an association of factors contributed to the recent reduction in the number of cases seen in the HC. These factors likely include seasonal variation (the end of winter), the presence of continuous epidemiologic monitoring and the provision of adequate information on prevention to the population.

We believe that the centered care associated with acquired expertise in H1N1 diagnosis and the adequate treatment that we provide to patients with the disease are responsible for the good results observed in the Hospital das Clínicas. Worldwide, after an initial decrease in the number of infections, it was observed that, during week 37 (September 13-19, 2009), influenza activity increased in the United States of America and in Europe. ${ }^{5,21}$

In the Hospital das Clínicas, we wish to maintain all the adopted measures described herein, with the ongoing objective of obtaining better outcomes in the management of novel influenza A (H1N1) infection. Through accumulating experience and continuing study of individual groups of patients, we hope to continuously contribute information regarding the epidemiology, pathogenesis and clinical aspects of this pandemic.

\section{REFERENCES}

1. Update: swine influenza A (H1N1) infections--California and Texas, April 2009. MMWR Morb Mortal Wkly Rep. 2009;58:435-7.

2. Update: novel influenza A (H1N1) virus infection - Mexico, March-May, 2009. MMWR Morb Mortal Wkly Rep. 2009;58:585-9.

3. Swine influenza A (H1N1) infection in two children--Southern California, March-April 2009. MMWR Morb Mortal Wkly Rep. 2009;58:400-2.

4. Dawood FS, Jain S, Finelli L, Shaw MW, Lindstrom S, Garten RJ et al Emergence of a novel swine-origin influenza A (H1N1) virus in humans. N Engl J Med. 2009;360:2605-15.

5. Pandemic (H1N1) 2009 - ECDC Daily Update. 2009. (Accessed September 26, 2009, at http://www.ecdc.europa.eu/en/healthtopics/ Documents/090925_Influenza_AH1N1_Situation_Report_0900hrs.pdf).

6. World Health Organization. Pandemic (H1N1) 2009 - update 62 (revised 21 August 2009) http://www.who.int/csr/don/2009_08_21/en/index.html (Accessed August 25, 2009)

7. United States Centers for Disease Control and Prevention. CDC telebriefing on investigation of human cases of novel influenza A (H1N1), June 26, 2009. http://www.cdc.gov/media/transcripts/2009/ t090626.htm (Accessed June 30, 2009).

8. ECDC working group on influenza $\mathrm{A}(\mathrm{H} 1 \mathrm{~N} 1) \mathrm{v}$. Preliminary analysis of influenza A (H1N1) individual and aggregated case reports from EU and EFTA countries. Eurosurveillance 2009, 14(23). Available from: http://www.eurosurveillance.org/ViewArticle.aspx?ArticleId=19238

9. Secretaria de Vigilância em Saúde. Informe epidemiológico Influenza A (H1N1). 2009; 1(8):1-10.

10. Brazilian Epidemiologic Report - Influenza A (H1N1). 2009. (Accessed August 24, 2009, at http://portal.saude.gov.br/portal/arquivos/pdf/ informe_influenza_se_32_publicacao_18ago2009.pdf.)

11. Diretrizes para o enfrentamento à pandemia de influenza A (H1N1): ações da atenção primária à saúde. (Accessed at http://portal.saude.gov. br/portal/arquivos/pdf/protocolo_influenza_aps_atualizado.pdf.)

12. Centers for Disease Control and Prevention. Update: novel influenza A (H1N1) virus infection - Worldwide. MMWR. 2009;58:453-8.
13. World Health Organization. Human infection with pandemic A (H1N1) 2009 influenza virus: clinical observations in hospitalized patients, Americas, July 2009 - update. Weekly epidemiological record 2009. http://www.who.int/wer/2009/wer8430/en/index.html (Accessed August 11, 2009).

14. Perez-Padilla R, de la Rosa-Zamboni D, Ponce de Leon S, Hernandez $\mathrm{M}$, Quiñones-Falconi F, Bautista E, et al. Pneumonia and respiratory failure from swine-origin influenza A (H1N1) in Mexico. N Engl J Med. 2009:361:680-89.

15. Chowell G, Bertozzi SM, Colchero MA, Lopez-Gatell H, AlpucheAranda C, Hernandez M, Miller MA. Severe respiratory disease concurrent with the circulation of H1N1 influenza. N Engl J Med. 2009;361:674-79.

16. Jamieson DJ, Honein MA, Rasmussen SA, Williams JL, Swerdlow DL, Biggerstaff MS, Lindstrom S, et al. H1N1 2009 influenza virus infection during pregnancy in the USA. Lancet. 2009;374:451-58.

17. United States Centers for Disease Control and Prevention. Interim guidance for clinicians on identifying and caring for patients with swine-origin influenza A (H1N1) virus infection http://www.cdc.gov/ swineflu/identifyingpatients.htm (Accessed May 5, 2009).

18. Ginocchio CC, Zhang F, Manji R, Arora S, Bornfreund M, Falk L, et al Evaluation of multiple test methods for the detection of the novel 2009 influenza A (H1N1) during the New York City outbreak. J Clin Virol. 2009;45:191-95.

19. Faix DJ, Sherman SS, Waterman SH. Rapid-test sensitivity for novel swine-origin influenza A (H1N1) virus in humans. N Engl J Med. 2009; 13;361(7):728-9.

20. United States Centers for Disease Control and Prevention. Interim guidance on specimen collection, processing, and testing for patients with suspected swine-origin influenza A (H1N1) virus infection. http:// www.cdc.gov/h1n1flu/specimencollection.htm (Accessed Septmber 20, 2009).

21. 2008-2009 Influenza Season Week 36 ending September 19, 2009. (Accessed September 25, 2009, at http://www.cdc.gov/flu/weeks). 